Article

\title{
Alternative Isolation Protocol for Desulfo and Zwitterionic Cylindrospermopsin Alkaloids and Comparison of Their Toxicity in HepG2 Cells
}

\author{
Carlos González-Blanco ${ }^{1,2,3}$, Felipe Augusto Dörr ${ }^{1}$, Renata Albuquerque ${ }^{1} \mathbb{D}$, Janice Onuki ${ }^{2} \mathbb{D}$ \\ and Ernani Pinto $1,4, *$ (D) \\ 1 Department of Clinical and Toxicological Analyses, School of Pharmaceutical Sciences, \\ University of São Paulo, São Paulo 05508-900, SP, Brazil; cgonzalezb@poder-judicial.go.cr (C.G.-B.); \\ fadorr@usp.br (F.A.D.); renatalb@usp.br (R.A.) \\ 2 Laboratory of Development and Innovation, Butantan Institute, Av. Vital Brasil, 1500, \\ São Paulo 05503-900, SP, Brazil; janice.onuki@butantan.gov.br \\ 3 Sección de Toxicología, Departamento de Ciencias Forenses, Organismo de Investigación Judicial, \\ Heredia 40801, Costa Rica \\ 4 Centre for Nuclear Energy in Agriculture, University of São Paulo, Piracicaba 13416-000, SP, Brazil \\ * Correspondence: ernani@usp.br; Tel.: +55-193429-4779
}

Received: 4 June 2020; Accepted: 29 June 2020; Published: 2 July 2020

\begin{abstract}
The term cylindrospermopsins (CYNs) refers to a structurally related class of cyanobacterial metabolites comprised of a tricyclic guanidine group and a hydroxymethyluracil moiety. Most reports in environmental aquatic samples refer to cylindrospermopsin (CYN), and reports on other CYN alkaloids are scarce, due, in part, to a lack of versatile isolation protocols. Thus, using commercially available solid phase extraction (SPE) cartridges, we optimized an isolation protocol for the complete recovery of CYN, 7-deoxy-cylindrospermopsin (7D-CYN) and 7-deoxy-desulfo-cylindrospermopsin (7D-desulfo-CYN) from the same aliquot. The isolation protocol was adaptable depending on the nature of the sample (solid biomass, culture broth or environmental water sample) and tolerates up to $4 \mathrm{~L}$ of dense culture broth or $400 \mathrm{mg}$ of lyophilized biomass. To quantitate the CYN alkaloids, we validated an LC-DAD-MS ${ }^{2}$ method, which takes advantage of the UV absorption of the uracil group ( $\lambda 262 \mathrm{~nm}$ ). Using electrospray ionization (ESI) in a positive ion mode, the high-resolution $\mathrm{MS}^{1}$ data confirms the presence of the protonated alkaloids, and the $\mathrm{MS}^{2}$ fragment assignment is reported as complementary proof of the molecular structure of the CYNs. We isolated three CYN alkaloids with different water solubility using the same lyophilized sample, with a purity that ranged from 95\% to $99 \%$. The biological activity of the purified CYNs, along with a synthetic degradation product of CYN (desulfo-cylindrospermopsin), was evaluated by assessing necrosis and apoptosis in vitro using flow cytometry. CYN's lethal potency in HepG2 cells was greater than the other analogs, due to the presence of all four functional groups: guanidine, uracil, C-7 hydroxyl and the sulfate residue.
\end{abstract}

Keywords: LC-MS²; LC-DAD; cylindrospermopsin; 7-deoxy-cylindrospermopsin; 7-deoxy-desulfocylindrospermopsin; cyanotoxins; HepG2 cells; biomass; culture broth

\section{Introduction}

The cyanotoxin cylindrospermopsin (CYN) is a worldwide health risk. Cylindrospermopsis (Raphidiopsis) raciborskii and other species capable of synthesizing this molecule have been reported in water bodies of tropical and temperate regions of Australia, North America, South America, New Zealand and Europe. However, cyanobacterial species capable of producing CYN and its 
structural variants are found in almost all of the world's latitudes [1,2]. In Brazil, the problem of cyanobacteria and their toxins in water is widely known and is a matter of public health policies [3-5].

Exposure to CYN produces a fatty liver and hepatonecrosis in experimental animals, with extrahepatic lesions of variable location and severity. The main toxic effects appear to be irreversible protein synthesis inhibition, oxidative stress and deoxyribonucleic acid (DNA) damage. Nevertheless, comprehensive and specific mechanisms of toxicity are yet unclear $[4,6]$.

Cylindrospermopsins (CYNs) are structural analogs of the originally reported CYN molecule. Limited information is available on the distribution, occurrence and toxicity of other naturally occurring CYN-like secondary metabolites from cyanobacteria [4,6,11-17]. Figure 1 shows the CYNs reported to date, along with their reported toxicity and calculated octanol/water partition coefficient $(\log \mathrm{P})$. CYN, 7-epi-cylindrospermopsin (7-epi-CYN) and 7-deoxy-cylindrospermopsin (7D-CYN) are the main zwitterions reported in freshwater samples and laboratory strains $[13,16,18]$. These zwitterion variants consist of a negatively chargeable sulfate group, a positively chargeable tricyclic guanidine portion and a biologically active uracil group. In the case of CYN and 7-epi-CYN, the uracil moiety is bound to the heterocyclic rings by a hydroxylated asymmetric carbon. This hydroxylation is absent in 7D-CYN, as well as in 7D-desulfo-CYN and 7-deoxy-desulfo-12-acetyl-cylindrospermopsin. Additionally, the absence of the sulfate anion on these last two desulfo variants makes them less hydrophilic compared to the zwitterion variants. Figure 1 also shows the structure of cylindrospermic acid and 5-chloro-cylindrospermopsin, two innocuous oxidation products reported in the literature. Desulfocylindrospermopsin (desulfo-CYN) is a degradation product that can be formed by acid hydrolysis.
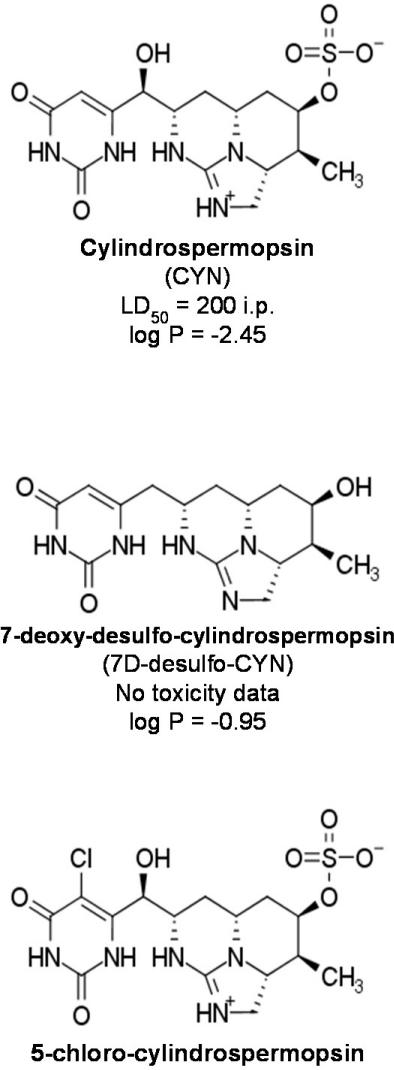

$$
\begin{aligned}
& L_{50}=>1000 \text { i.p. } \\
& \log P=-1.89
\end{aligned}
$$
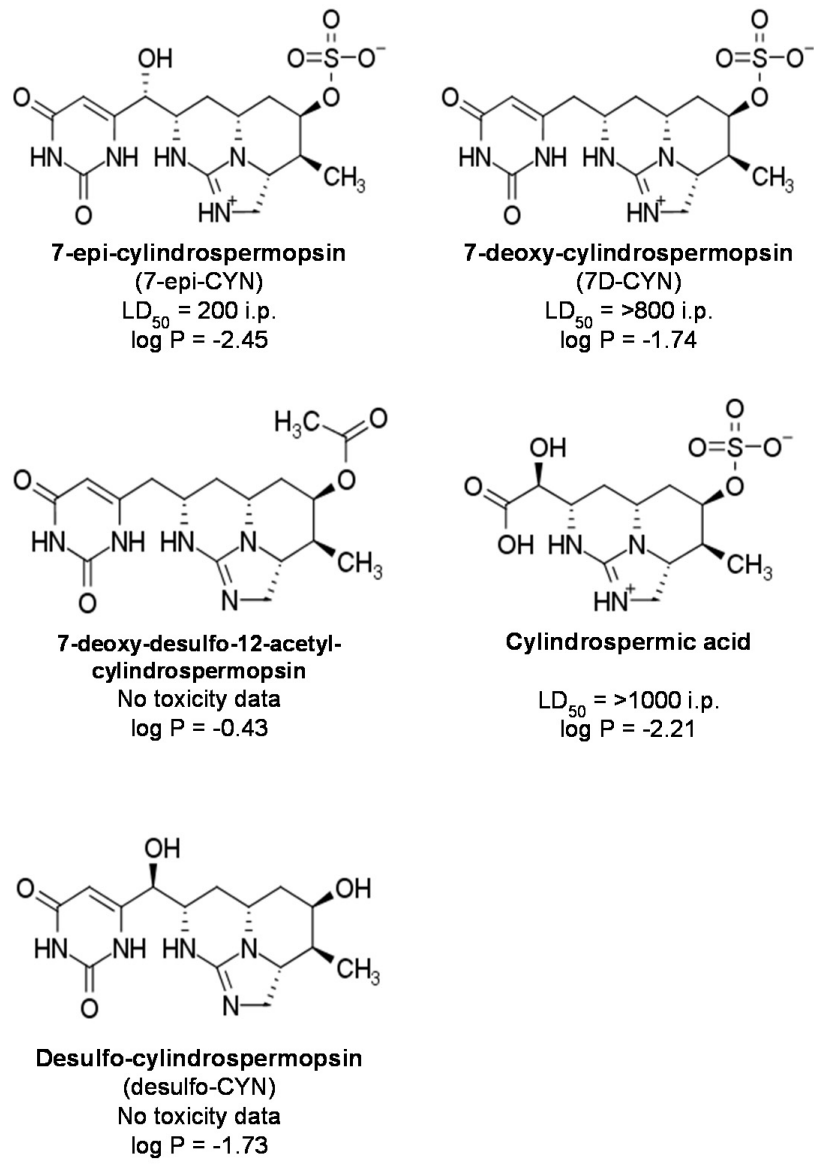

Figure 1. Structure, toxicity and theoretical $\log \mathrm{P}$ of natural cyanotoxin cylindrospermopsin (CYN) alkaloids and degradation products. $\mathrm{LD}_{50}(\mu \mathrm{g} / \mathrm{kg})$ refers to the median lethal dose in mice, administered by intraperitoneal (i.p.) injection. Theoretical $\log P$ corresponds to the arithmetic mean of the values calculated by online cheminformatics tools (see Table S1 for details) [7-10]. 
Both 7D-CYN and 7D-desulfo-CYN are biosynthetic precursors of the originally reported CYN molecule. The functional guanidino moiety is the starting unit in the biosynthesis of the carbon backbone of CYN. An uncommon biosynthetic pathway of pyrimidine is responsible for the de novo formation of the uracil ring. Finally, sulfation and hydroxylation tailoring reactions add the last modifications that culminate in the fully bioactive cylindrospermopsin molecule $[19,20]$.

Cylindrospermopsin is a widely studied molecule for which numerous extraction protocols and toxicity assays have been described. 7D-CYN is a zwitterion analog, structurally similar enough to be simultaneously isolated along with CYN in most frequently used extraction protocols [11,13,21,22]. However, other CYN-like metabolites are less reported. In 2014, Wimmer et al. reported the natural occurrence of two alkaloids with different hydrophobicity than the previously reported CYNs: 7D-desulfo-CYN and 7-deoxy-desulfo-12-acetylcylindrospermopsin [15]. At present, there are no certified standards for 7D-desulfo-CYN and 7-deoxy-desulfo-12-acetylcylindrospermopsin. 7D-CYN-certified standards are available by several vendors. Nevertheless, 7D-CYN standards are currently sold in low concentrations that are inappropriate for the validation of analytical methods or biological testing purposes.

The chemical properties of the less-hydrophilic CYNs indicate that they may accumulate in other matrixes other than freshwater-for example, inside cyanobacterial cells, animal tissue, sediments or water filter resins. The distribution of desulfo CYNs in ecological systems is unknown.

7D-desulfo-CYN serves as an important analyte in order to study the importance of the C-7 hydroxylation in the lethal potency of CYN alkaloids that lack the sulfate group. Another desulfo analog, desulfo-CYN, can be synthesized by the acid hydrolysis of CYN at a constant temperature. Reports on the acute toxicity of desulfated CYNs are scarce, and the chronic effects of these desulfo variants are far from being elucidated. Here, we report a novel SPE workflow to isolate cylindrospermopsins (CYN, 7D-CYN and 7D-desulfo-CYN) simultaneously from the same aliquot of a natural producing strain in order to assess their lethal potencies on HepG2 cells.

\section{Results}

\subsection{Tests on Sample Size and Cartridge Handling}

According to previous analysis from our group, the C. raciborskii $11 \mathrm{~K}$ strain produces high quantities of CYN and 7D-CYN, a great part of which is secreted to the culture medium (data not shown). There was also evidence of a third CYN natural alkaloid, which was later confirmed as 7D-desulfo-CYN. In order to selectively isolate these metabolites, our initial approach was to separate them from a simple liquid matrix (filtered culture medium) using SPE cartridges. Subsequently, we tested the performance of SPE sorbents on a more complex solid matrix (lyophilized culture biomass).

\subsubsection{Liquid Samples}

CYN and 7D-CYN are heavily secreted and are available in high quantities in the culture medium of C. racibosrkii 11k. As stated earlier, 7D-desulfo-CYN is less hydrophilic, and it is scarce in the aqueous culture medium.

Small-scale experiments using liquid medium were performed initially in the liquid sample to assess the adsorption of the analytes (mostly CYN and 7D-CYN) on two SPE columns: graphitized nonporous carbon (GNPC) and C18 (Figures S1-S5). The adsorbed analytes were eluted using four different methanol (MeOH) concentrations (Figures S2-S5). CYN and 7D-CYN showed high affinity for the GNPC stationary phase, and it became necessary to elute the carbon cartridges in backflush mode. Backflush elution refers to the reverse use of the SPE cartridge, where the liquid flow enters the cartridge through the bottom frit and exits by the top frit.

The GNPC cartridge is not particularly designed for backflush mode, although it can be improvised. Nevertheless, eluting with various $\mathrm{MeOH}$ concentrations with the GNPC cartridge in backflush mode 
was challenging. Thus, we tested a modified version of the elution technique reported by Norris et al. (2001) [17]. In this manner, we used $\mathrm{MeOH}: \mathrm{CH}_{2} \mathrm{Cl}_{2} 4: 1$ with 5\% formic acid (FA) to elute the analytes without needing to backflush the cartridge. Table S2 shows the percent recovery of the three CYN variants when extracted from GNPC cartridges using two kinds of elution techniques. The elution performance for CYN using MeOH: $\mathrm{CH}_{2} \mathrm{Cl}_{2} 4: 1(v / v)$ with $5 \%$ formic acid yielded a better percent recovery than the backflush-mode technique. Elution using $\mathrm{MeOH}: \mathrm{CH}_{2} \mathrm{Cl}_{2}$ 4:1 with 5\% FA needed no adaptation, as is required when eluting in backflush mode. Since the MeOH:CH $\mathrm{Cl}_{2} 4: 1$ with 5\% FA elution was easier and more efficient for cylindrospermopsin, it was chosen as the elution method for the subsequent isolation experiments.

\subsubsection{Solid Samples}

Compared to the liquid medium, the remaining biomass from the broth extraction experiments contained the three CYN variants in higher concentrations. The recovered biomass comprises mostly on intact cyanobacteria separated by centrifugation, and it constitutes a complex matrix compared to the broth. Compared to the culture medium, the less hydrophilic alkaloid 7D-desulfo-CYN is stocked in higher concentrations inside the cells. In order to recover a cleaner extract of 7D-desulfo-CYN, we decided to include an extra SPE step before the GNPC extraction.

Therefore, we tested the affinity of 7D-desulfo-CYN to C18 and HLB cartridges using the remaining biomass from the liquid samples experiments (Materials and Methods 4.3). HLB and C18 cartridges retained 7D-desulfo-CYN with similar performances at the samples' natural $\mathrm{pH}(7.5 \pm 0.5)$. Elution of the cartridges with $10 \mathrm{~mL}$ of $15 \% \mathrm{MeOH}$ selectively rinsed CYN and 7D-CYN from the column's sorbent. The following fraction eluted with $100 \% \mathrm{MeOH}$ contained the 7D-desulfo-CYN analog. Fewer contaminants were detected in this last elution step while using C18 columns.

In this manner, the aqueous extract from the lyophilized biomass requires an extra step involving a C18 cartridge to retain 7D-desulfo-CYN. Next, an elution with 15\% MeOH is needed to rinse CYN zwitterions and other highly hydrophilic metabolites from the C18 column into another cartridge. A GNPC cartridge can be adapted in series to the C18 column to adsorb CYN and 7D-CYN, as reported by Wimmer et al. (2014) [15].

Preliminary tests using acyclovir as internal standard (IS) showed a good affinity for the GNPC cartridge and C18 column (data not shown). Usually, the IS is applied directly to the intact sample. Nevertheless, in the case of solid samples, acyclovir can be partially eluted during Step 4a of the extraction protocol (Figure 2). We proposed adding the IS directly to the SPE columns (Figure 2, Steps 7a and $6 b$ ) for the protocol to be compatible with quantitative analysis. The IS was added in this manner during the validation experiments, as described in Materials and Methods (4.5-4.6).

Finally, a summarized version of the whole workflow is displayed in Figure 2. The capacity of the tested SPE columns allows handling up to $0.4 \mathrm{~g}$ of lyophilized cells or $4 \mathrm{~L}$ of filtered broth. The workflow was designed for the purification or the absolute quantitation of CYN variants simultaneously in the same sample.

\subsection{Validation of the LC-DAD Method for CYNs Quantitation}

CYN alkaloids produced by the C. raciborskii $11 \mathrm{~K}$ strain display an uracil moiety, which absorbs $\mathrm{UV}$ radiation at a $\lambda_{\max }$ (maximum wavelength) of $262 \mathrm{~nm}$. In order to quantify CYNs available in the samples, we took advantage of this shared functional group. At the time the experiments were designed, only CYN-certified standards were commercially available in enough quantities to perform validation protocols. Liquid sample extracts used for validation experiments were prepared as described in Figure 2, Steps 1b-7b. The validation guidelines and the liquid chromatography coupled to a diode-array detector (LC-DAD) method parameters are described in Materials and Methods, items 4.6 and 4.7, respectively. 


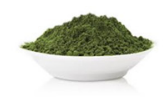

$0.1-0.4 \mathrm{~g}$ of solid sample (e.g., lyophilized culture biomass or lyophilized bloom sample). In these matrices less hydrophilic CYNs, as well as highly hydrophilic CYNs are expected.

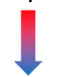

Step 1a: Extract with $20 \mathrm{~mL}$ of $\mathrm{H}_{2} \mathrm{O}$, followed by 20 $\mathrm{mL}$ of $\mathrm{MeOH}: \mathrm{H}_{2} \mathrm{O}$ (1:1). Vortex, spin (10000 rpm) after each extraction. Filter supernatant with a 0.44 $\mu \mathrm{m}$ membrane filter. Add water to a final volume of 1 $\mathrm{L}(1 \% \mathrm{MeOH})$.

Step 2a: Adapt a $1 \mathrm{~g}$ GNPC cartridge in series to the end of a 0.5. $\mathrm{g}$ C18 cartridge on a SPE manifold. Condition ${ }^{\mathrm{a}}$ both cartridges.

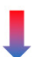

Step 3a: Install PTFE tubing and tube adapters Transfer the sample through the cartridges at a flow rate of $1 \mathrm{dps}$.

Step 4a: Uninstall the PTFE tubing system. Apply $10 \mathrm{~mL} 15 \% \mathrm{MeOH}$ to the connected cartridges; this will elute remaining hydrophilic CYNs from the first cartridge into the GNPC cartridge.

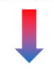

Step 5a: Separate and re-install the $\mathrm{C} 18$ cartridge to the manifold.

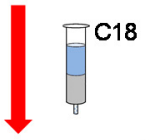

Step 6a: The $\mathrm{C} 18$ phase contains the less hydrophilic CYNs.

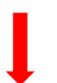

Step 7a (optional, only for quantitation purposes*): If the goal is to quantitate hydrophobic CYNs in an unknown sample, condition the $\mathrm{C} 18$ cartridge with $6 \mathrm{~mL}$ of $\mathrm{H}_{2} \mathrm{O}$, followed by $6 \mathrm{~mL}$ of $\mathrm{H}_{2} \mathrm{O}$ containing IS**.

Step 8a: Dry the sorbent, under vacuum for $5 \mathrm{~min}$ Elute with $10 \mathrm{~mL}$ of $100 \% \mathrm{MeOH}$. This will release desulfo-CYN variants like 7D-desulfo-CYN.

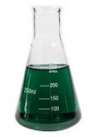

$1 \mathrm{~L}-4 \mathrm{~L}$ of aqueous sample (e.g., culture broth, surface water sample, etc). In these matrices mostly hydrophilic CYNs are expected.

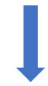

Step 1b: Spin sample at $10000 \mathrm{rpm}$. Collect and filter the supernatant with a $0.44 \mu \mathrm{m}$ membrane filter.

Step 2b: Condition ${ }^{\alpha}$ a $1 \mathrm{~g}$ GNPC cartridge on a SPE manifold ${ }^{\beta}$.

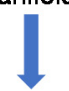

Step 3b: Install PTFE tubing and tube adapters Transfer the sample through the cartridge at a flow rate of $1 \mathrm{dps}$

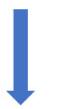

Step 4b: Uninstall the PTFE tubing system.

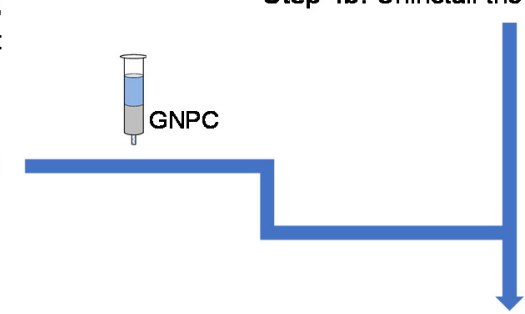

Step 5b: The GNPC phase contains the most hydrophilic CYNs.

Step $6 \mathrm{~b}$ (optional, only for quantitation purposes*): If the goal is to quantitate hydrophilic CYNs in an unknown sample, condition the cartridge with $6 \mathrm{~mL}$ of $\mathrm{H}_{2} \mathrm{O}$, followed by $6 \mathrm{~mL}$ of $\mathrm{H}_{2} \mathrm{O}$ containing IS*

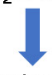

Step 7b: Dry the sorbent under vacuum for 5 min. Elute with $10 \mathrm{~mL}$ of $\mathrm{MeOH}: \mathrm{CH}_{2} \mathrm{Cl}_{2}$ (4:1) $5 \%$ FA. This will release zwitterionic species like $7 \mathrm{D}$ CYN and CYN.

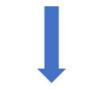

\begin{tabular}{lr} 
7D-desulfo-CYN & 7D-CYN \\
\hline Less hydrophilic & More hydrophilic
\end{tabular}

Figure 2. Proposed workflow for the simultaneous purification of zwitterionic (more hydrophilic) and desulfo (less hydrophilic) cylindrospermopsin analogs from cyanobacteria biomass, culture broth or surface water samples. MeOH: methanol, SPE: solid-phase extraction, GNPC: graphitized nonporous carbon, PTFE: polytetrafluoroethylene, IS: internal standard, $\mathrm{CH}_{2} \mathrm{Cl}_{2}$ : dichloromethane, $\mathrm{FA}$ : formic acid and dps: drop per second. ${ }^{\alpha}$ Condition both cartridges with $\mathrm{MeOH}$, followed by deionized $\mathrm{H}_{2} \mathrm{O}$. Do not let the sorbents dry up in this step. ${ }^{\beta}$ Less-hydrophilic desulfo CYNs on aqueous samples are negligible; therefore, C18 cartridges are not necessary. * The IS must be added at this point if the extraction's objective is the simultaneous quantitation of zwitterionic and desulfo CYNs. Spiking solid samples with IS is not recommended for this protocol, because acyclovir (IS) adsorbs to both sorbents (GNPC and C18). The resulting uneven distribution of the IS in both sorbents impedes the simultaneous quantitation of the CYN variants. ** Acyclovir was used as the IS. 
Selectivity was assessed by testing for matrix effects and by calculating the peak resolution (Rs) from the UV-extracted chromatogram at $\lambda 262 \mathrm{~nm}$. The matrix effect was evaluated by investigating the presence of interference signals (on the analytes' retention times) using extracts from blank samples. Regarding the matrix effect, all tested samples were considered acceptable according to the criteria indicated in Materials and Methods 4.6. Likewise, chromatographic selectivity was assessed by calculating Rs for CYN and four other analytes in a nonextracted mix. Figure $\mathrm{S} 8$ shows a suitable peak resolution $\left(\mathrm{R}_{\mathrm{S}} \geq 2\right.$ ) for CYN, 7D-CYN, 7D-desulfo-CYN, desulfo cylindrospermopsin (desulfo-CYN) and the IS (acyclovir). Desulfo-CYN is an in-house synthesized degradation product of CYN, developed as detailed in Materials and Methods 4.6.

The uracil moiety is a requisite for the quantitation of CYN-like metabolites using the validated LC-DAD method. The hydroxymethyluracil functional group is essential for CYN's toxicity and is present in all of the natural CYNs described to date, unlike the sulfate group [12,13,15,16,23-25]. The quantitation of 7D-CYN, 7D-desulfo-CYN and desulfo-CYN was carried out by interpolating their normalized peak area into the calibration curve of the cylindrospermopsin-certified standard.

\subsection{Identity and Purity of Isolated CYN Analogs}

All CYN structural variants extracted by SPE underwent an extra LC-DAD purification step with a C18 semipreparative column using a chromatographic method described in the Materials and Methods (item 4.4). This extra purification step was needed in order to separate CYN and 7D-CYN from the same SPE fraction and eliminate the impurities. On the other hand, the 7D-desulfo-CYN isolated with C18 cartridges had few impurities left. Nevertheless, it was also subjected to the same LC-DAD isolation step.

\subsubsection{Purity Assessment Using LC-DAD-MS²}

The purity of the isolated CYN analogs was determined from the UV-extracted chromatogram at $\lambda 262 \mathrm{~nm}$. The purity of the isolated CYNs ranged from $97 \%$ to $99 \%$. Figure 3 shows an example of three lots of purified alkaloids, analyzed by liquid chromatography coupled to a diode-array detector and connected to a tandem mass spectrometer (LC-DAD-MS ${ }^{2}$ ). The extracted ion chromatogram (EIC) of the protonated precursor ion (acquired by the quadrupole time-of-flight-QTOF-analyzer) and the UV spectrum (acquired by the diode-array detector) confirm the identity of each purified CYN analog (Figure 3).

\subsubsection{Molecular Structure Confirmation Using LC-DAD-MS ${ }^{2}$}

All three naturally occurring CYN alkaloids (Table 1 ) were identified with mass accuracy $<1.6 \mathrm{ppm}$, considering the mass error of the protonated precursor ion $\left(\mathrm{MS}^{1}\right)$. These measures were performed on different days $(n=3)$.

Table 1. Mean measured and calculated monoisotopic $m / z$ value (including the mean error) of the protonated precursor ion $\left(\mathrm{M}+\mathrm{H}^{+}\right)$of each of the isolated cylindrospermopsins. All measures were performed on a QTOF mass analyzer.

\begin{tabular}{cccc}
\hline \multirow{2}{*}{ Analyte } & $\begin{array}{c}\text { Mean Measured } \mathbf{M}+\mathbf{H}^{+} \\
(\mathbf{m} / \mathbf{z}) \mathbf{n}=\mathbf{3}\end{array}$ & $\begin{array}{c}\text { Calculated } \mathbf{M}+\mathbf{H}^{+} \\
(\mathbf{m} / \mathbf{z})\end{array}$ & Mean Error (ppm) \\
\hline CYN & 416.1235 & 416.1240 & 1.2 \\
7D-CYN & 400.1288 & 400.1291 & 0.87 \\
7D-desulfo-CYN & 320.1728 & 320.1723 & 1.6 \\
\hline
\end{tabular}

The fragmentation pattern of CYNs in the gas phase was studied using the three purified metabolites. The QTOF mass analyzer was set in multiple reaction monitoring (MRM) mode to perform collision-induced dissociation (CID) experiments at the following collision energies: $20 \mathrm{eV}, 35 \mathrm{eV}$ and $40 \mathrm{eV}$. The collision energies included in Figure 4 generated a reproducible and rich mass spectra. 


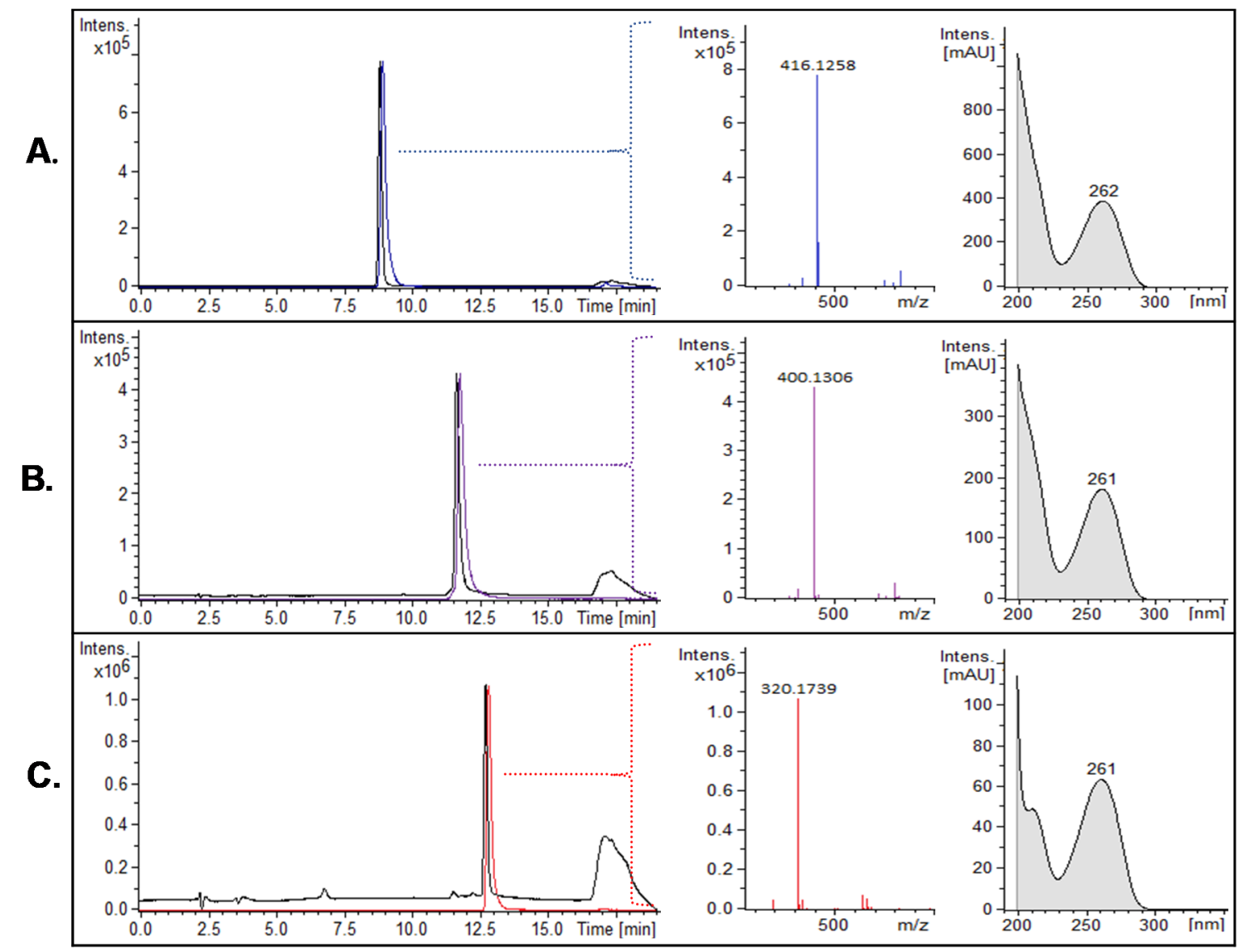

Figure 3. Purity assessment of three isolated CYNs: (A) CYN, (B) 7D-CYN and (C) 7D-desulfo-CYN. Every subfigure shows, in sequential order: overlapped EIC * (colored chromatogram) and EC ** at $\lambda$ $262 \mathrm{~nm}$ (black chromatogram), the protonated precursor's $\mathrm{m} / \mathrm{z}$ (colored mass spectrum) and the UV absorption spectrum. * EIC: extracted ion chromatogram (MS) of the protonated precursor ion. ${ }^{* *}$ EC: extracted chromatogram (UV). mAU: milli-absorbance unit.

A partial assignment of adducts and fragments of CYN and 7D-CYN was described by Norris et al. (1999) [13]. Later, ion trap fragmentation studies of CYN metallic adducts confirmed the CID (collision-induced dissociation) reactions that precursors underwent in the gas phase of the mass analyzer [26]. The structure of the most intense MS ${ }^{2}$ ions of 7D-CYN and 7D-desulfo-CYN (Figure 4) was successfully assigned based solely on the gas-phase fragmentation reactions proposed by Dörr et al. (2008). The resulting spectra were useful in order to compare the fragmentation patterns of 7D-CYN and 7D-desulfo-CYN (Figure 4).

\subsubsection{Toxicity Assessment Using Flow Cytometry}

Previously reported cell proliferation testing using MTT (3-(4,5-dimethylthiazol-2-yl)-2,5diphenyltetrazolium bromide) gave us a starting point from which to choose appropriate concentrations of CYNs for the cell stimulation. The MTT assay evaluates the mitochondrial dehydrogenase activity of cells by measuring the formation of formazan crystals. In one study, the MTT assay yielded an $\mathrm{IC}_{50}$ (half-maximal inhibitory concentration) of $1.5 \pm 0.9 \mu \mathrm{M}$ after a 24-h stimulation with CYN in HepG2 cells [27].

Likewise, two studies found no significant differences between the vehicle control and CYN-treated HepG2 cells at $0.5 \mu \mathrm{g} / \mathrm{mL}$ [28] and $2 \mu \mathrm{g} / \mathrm{mL}$ [29] after $24 \mathrm{~h}$.

In this work, we initially required the calculation of the threshold concentrations of the CYN analytical standard that significantly decreased HepG2 cells' viability in the relevant time intervals. 
Next, we wanted to use the previously defined threshold concentrations to treat HepG2 cells with the purified CYNs (to calculate their toxicity). The effects of the purified CYN variants on HepG2's viability measured by flow cytometry could later be compared to previously published data to evaluate the isolated CYN variants' potency.

For this purpose, HepG2 cells were stimulated with different concentrations of the CYN analytical standard (Abraxis ${ }^{\circledR}$ ) for up to $48 \mathrm{~h}$ (Figure 5D). No significant viability decrease was detected by the flow cytometry assay on HepG2 cells using $1 \mu \mathrm{M}$ of CYN for a 24-h time interval. In a 48-h treatment, a stimulation with $0.5 \mu \mathrm{M}$ of CYN did not induce apoptotic nor necrotic effects, while higher concentrations $(1 \mu \mathrm{M}$ and $5 \mu \mathrm{M})$ caused a significant viability decrease on the cell cultures.

In the same manner, we treated HepG2 cells with the purified CYN alkaloids (Figures 6 and 7) to compare their potency against the commercial CYN standard. We also tested the biological activity of the degradation product desulfo-CYN (Figure 7).

Figure 6D indicates that, after a 48-h treatment, the purified CYN standard (lot 2016.07.03) showed a lethality on HepG2 cells compared to the lethality of the certified CYN standard (Abraxis ${ }^{\circledR}$ ).

On the other hand, cells stimulated with 7D-CYN, 7D-desulfo-CYN and desulfo-CYN showed no significant difference in viability compared to their respective controls at the tested conditions (Figures 6 and 7).

A.
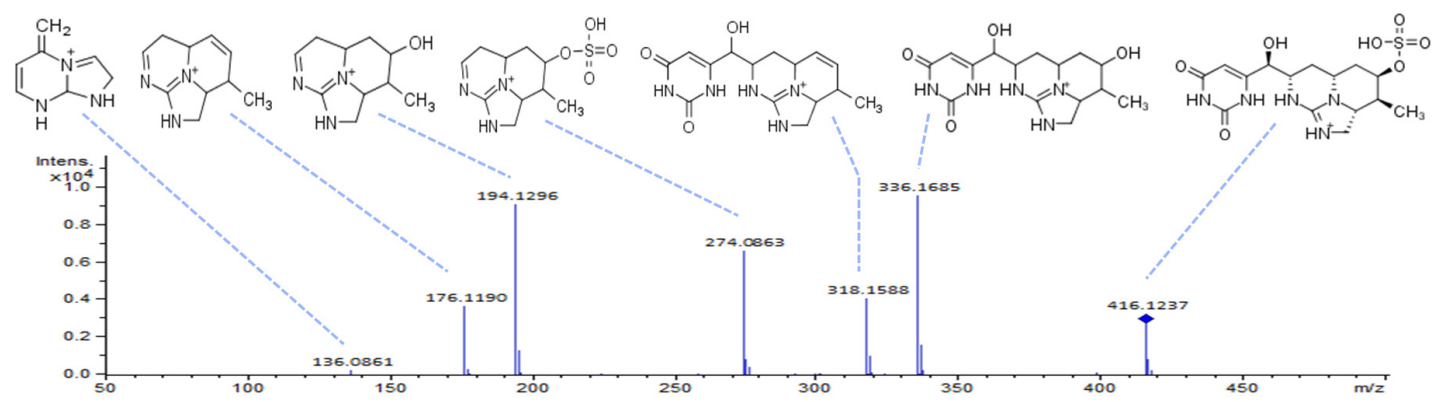

B.

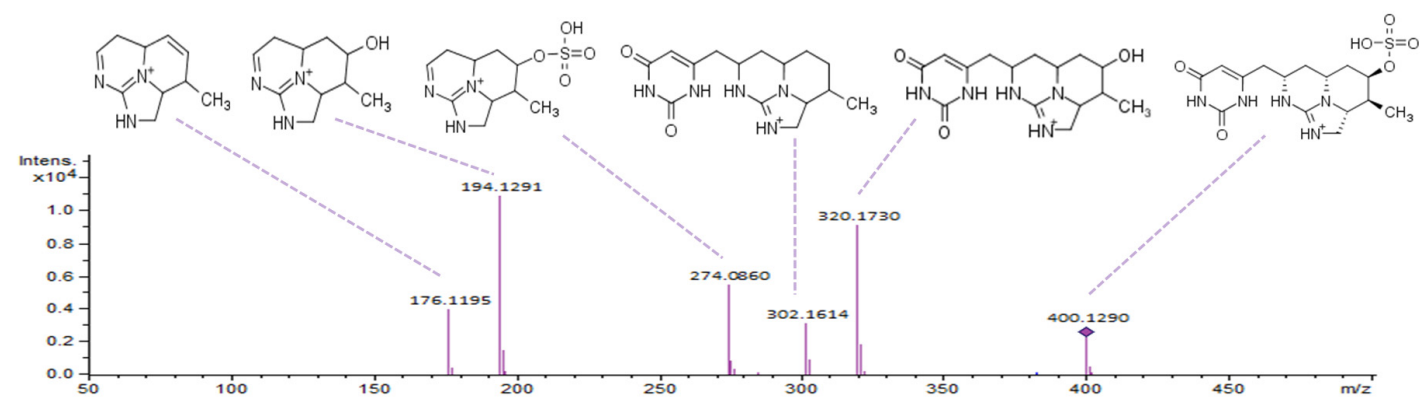

C.

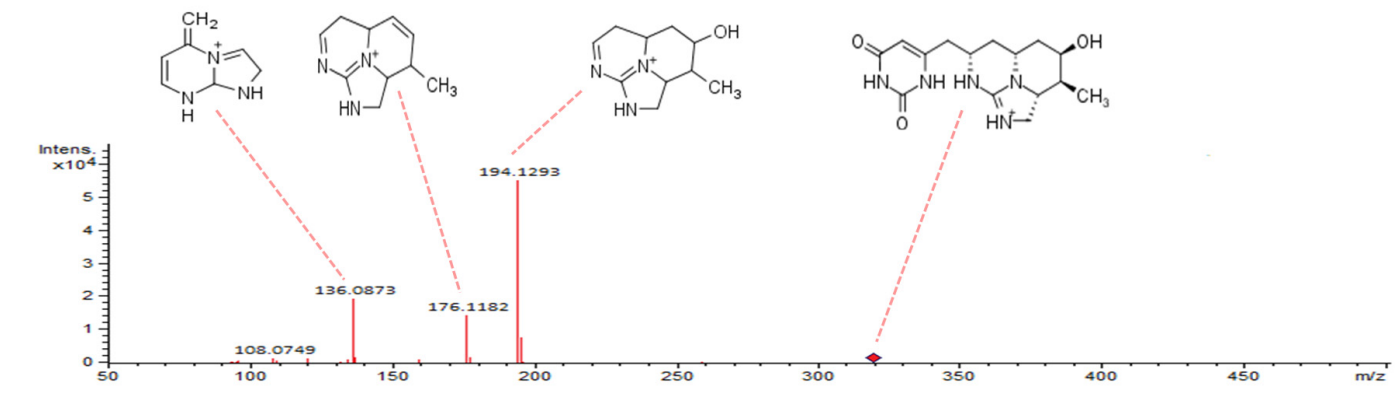

Figure 4. Proposed structure assignment of CYNs fragmentation patterns on a QTOF mass analyzer: (A) CYN at $20 \mathrm{eV}$, (B) 7D-CYN at $20 \mathrm{eV}$ and (C) 7D-desulfo-CYN at $35 \mathrm{eV}$. Structure assignment was based on previous calculations by Dörr et al. (2010) [26]. 

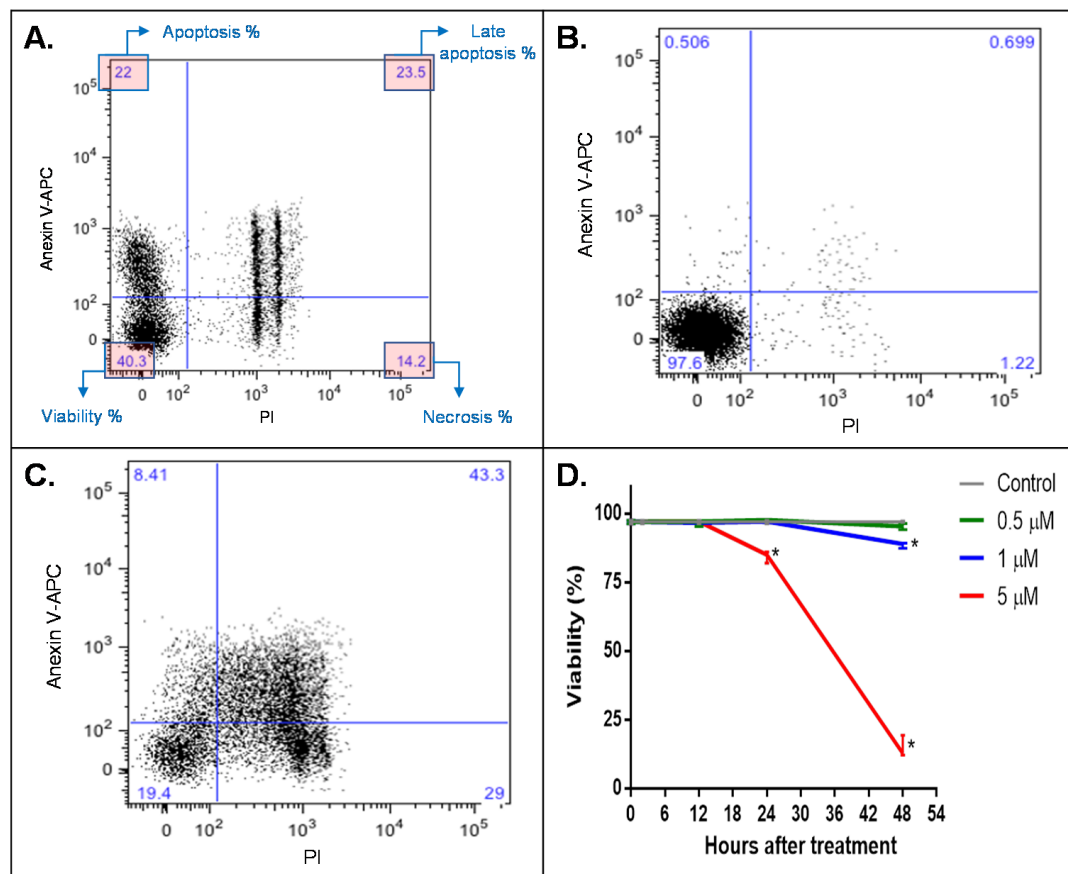

Figure 5. Biological activity of the CYN-certified standard (Abraxis ${ }^{\circledR}$ ) on HepG2 cells, analyzed by flow cytometry using propidium iodide (PI) as the necrosis marker and annexin V-APC as the apoptosis marker: (A) Example of viability percentage (\%) of a 24-h apoptosis and necrosis positive control. (B) Example of a 24-h negative control. (C) Example of a 48-h treatment with 5- $\mu$ M CYN. (D) Viability after treatment using $0.5,1$ and $5 \mu \mathrm{M}$ of CYN for 12,24 and $48 \mathrm{~h}(\mathrm{n}=4)$. APC: allophycocyanin; statistical comparisons between groups (control vs. treatment) were performed using Mann-Whitney $\mathrm{U}$ tests; $p<0.05$. ${ }^{*}$ Statistically significant group compared to the control group.
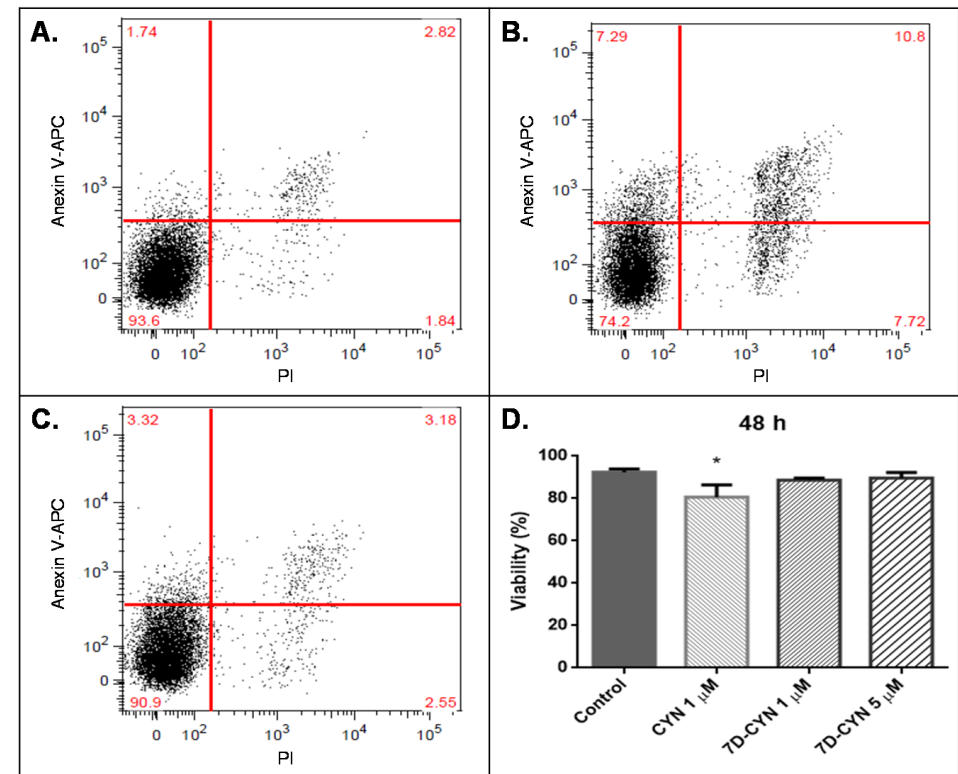

Figure 6. Biological activity of CYN and 7D-CYN purified from C. raciborskii $11 \mathrm{~K}$ on HepG2 cells analyzed by flow cytometry using propidium iodide (PI) as the necrosis marker and annexin V-APC as the apoptosis marker: (A) Example of a 48-h negative control. (B) Example of a 48-h treatment with $1 \mu \mathrm{M}$ CYN. (C) Example of a 48-h treatment with $5 \mu \mathrm{M}$ 7D-CYN. (D) Viability after treatment using $1 \mu \mathrm{M} C Y N$ and 1 and $5 \mu \mathrm{M} 7 \mathrm{D}-\mathrm{CYN}(\mathrm{n}=4)$. APC: allophycocyanin; statistical comparisons between groups (control vs. treatment) were performed using Mann-Whitney $\mathrm{U}$ tests; $p<0.05$. ${ }^{*}$ Statistically significant group compared to the control group. 


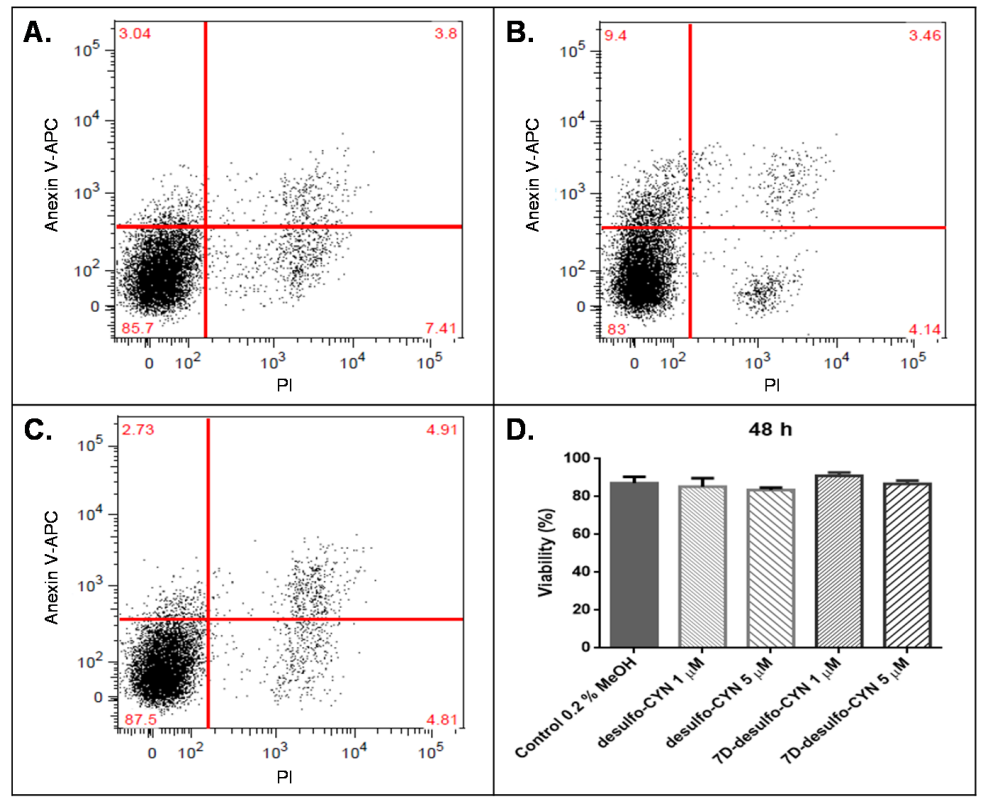

Figure 7. Biological activity of desulfo-CYN and 7D-desulfo-CYN purified from C. raciborskii $11 \mathrm{~K}$ on HepG2 cells analyzed by flow cytometry using propidium iodide (PI) as the necrosis marker and annexin $\mathrm{V}$-APC as the apoptosis marker. (A) Example of a 48-h negative control $0.2 \% \mathrm{MeOH}$. (B) Example of a 48-h treatment with $5 \mu \mathrm{M}$ desulfo-CYN. (C) Example of a 48-h treatment with $5 \mu \mathrm{M}$ 7D-desulfo-CYN. (D) Viability after a 48-h treatment using 1 and $5 \mu \mathrm{M}$ of desulfo-CYN and 7D-desulfo-CYN (n = 4). APC: allophycocyanin signal; statistical comparisons between groups (control vs. treatment) were performed using Mann-Whitney U tests; $p<0.05$.

\section{Discussion}

We present in this work new comparative toxicological studies in vitro of zwitterionic and desulfated CYN alkaloids. Comparative studies between naturally occurring CYN alkaloids are not common, mainly due to a lack of popular and accepted extraction protocols for these metabolites.

The workflow described in Figure 2 aims to improve the monitoring of CYNs by concurrently isolating CYN variants with different water solubilities, depending on the nature of the sample. As evidenced in Figures S1-S7, considerable effort was invested in testing different SPE sorbents' abilities to retain the CYN analogs after applying various elution techniques. Our main concern was to implement efficient and selective elutions on the ideal sorbent, while ensuring the maximum recovery of each analyte.

Norris et al. (2001) documented the benefits of using graphitized carbon cartridges (instead of C18) to retain CYN zwitterions [17]. Nevertheless, C18 SPE columns proved optimal in order to selectively adsorb less-hydrophilic CYNs [15]. The coupling of these two SPE techniques while using selective eluents can improve the recovery of each unique CYN-like molecule.

Unknown solid samples composed mostly of the biomass may contain highly hydrophilic and, also, less-hydrophilic CYNs. As shown in Figure 2 (Step 2a), after the application of the sample to the coupled cartridges, less-hydrophilic variants remain in the C18 phase, while zwitterions adsorb mainly on GNPC. Elution with $15 \% \mathrm{MeOH}$ efficiently releases the remaining zwitterions from the $\mathrm{C} 18$ phase, and these, in turn, adsorb to the GNPC cartridge. Desulfo-CYNs in an unknown sample will remain in the $\mathrm{C} 18$ phase and can be subsequently eluted with pure $\mathrm{MeOH}$. On the other hand, hydrophilic zwitterions bond strongly to the GNPC phase, and pure acidified $\mathrm{MeOH}$ is not sufficient to completely release these metabolites from the solid phase. However, the complete recovery of zwitterions from the carbon phase was reliably achieved with $10 \mathrm{~mL}$ of $\mathrm{MeOH}: \mathrm{CH}_{2} \mathrm{Cl}_{2}$ 4:1 with 5\% FA; there was no need for successive elutions, even when extracting $0.4 \mathrm{~g}$ of the biomass from our toxin-producing strain. 
The validation of the protocol only focused on CYN, due to the lack (at the time) of commercially available certified standards of 7D-CYN at concentrations useful to prepare spiked samples. As stated earlier, no certified standards of 7D-desulfo-CYN (or other desulfo alkaloids) are currently available. Consequently, we decided to only include in the validation plan steps $1 \mathrm{~b}$ to $7 \mathrm{~b}$ of the workflow (Figure 2). As indicated in the Results (Section 2.2) and Supplementary Materials (Figures S8 and S9 and Tables S3 and S4), all the analytical performance parameters evaluated in the validation were under regulatory guidance requirements.

After confirming the quantity, purity and structure of the metabolites, we carried out toxicity assays on HepG2 cells. Fluorescence-activated cell sorting (FACS) flow cytometry was chosen as the ideal technique to test the purified CYNs' toxicity. Some benefits of using FACS are that it monitors a representative sample of our cells (10,000 events), it is selective enough to identify the type of cell death (necrosis or apoptosis) and it is a highly sensitive technique because of the use of fluorescent markers.

Toxicity data resulting from our experiments matched the CYNs' cell death results reported by Štraser et al. (2013) using annexin V and PI staining for FACS analysis. Their research found no significant difference in cell death between the vehicle control and treated HepG2 cells at $0.5 \mu \mathrm{g} / \mathrm{mL}$ for 12 and $24 \mathrm{~h}$ [30]. Using a similar methodology (Figure 5D), we did not find a significant difference in cell death between the control (100\% viability) and cells treated with $1 \mu \mathrm{M}(0.4 \mu \mathrm{g} / \mathrm{mL})$ of the certified CYN standard during 12 and $24 \mathrm{~h}$. Additionally consistent with Štraser et al.'s work, significant cell death was detected after a 48 -h stimulation with $1 \mu \mathrm{M}$ of the CYN-certified standard (Figure 5D) and $1 \mu \mathrm{M}$ of purified CYN (Figure 6D). Intriguingly, a two-h treatment with $381 \mu \mathrm{M}$ of CYN showed no significant viability decrease (data not shown). This was the highest concentration we could prepare with the available CYN-certified standard. Even though it is not a practical working concentration, the results with $381 \mu \mathrm{M}$ of CYN served as evidence of the cyanotoxin's delayed toxicity. In other words, the toxin's apoptotic and/or necrotic effects are not immediate to HepG2 cells even at high concentrations.

In our current work, 7D-CYN caused no significant loss in viability at $1 \mu \mathrm{M}(0.4 \mu \mathrm{g} / \mathrm{mL})$ and $5 \mu \mathrm{M}$ $(2.0 \mu \mathrm{g} / \mathrm{mL}$ ) after a $48-\mathrm{h}$ treatment (Figure 6D). These results are consistent with reports by Neumann et al. (2007). Their group implemented a cell proliferation assay using the 3-(4,5-dimethylthiazol-2-yl)-5(-3-carboxymethoxyphenyl)-2-(4-sulfophenyl)-2H-tetrazolium inner salt (MTS) and the electron-coupling reagent phenazine ethosulfate (PES). They stimulated with 7D-CYN several cell lines—of which, HepG2 was the least affected-yielding an $\mathrm{IC}_{50}$ of $3.2 \mu \mathrm{g} / \mathrm{mL}$ at $24 \mathrm{~h}$ and $3.1 \mu \mathrm{g} / \mathrm{mL}$ at $48 \mathrm{~h}$ [12]. According to Looper et al. (2005), 7D-CYN is a potent inhibitor of protein synthesis in vitro. Nevertheless, a complete protein synthesis inhibition required $10 \mu \mathrm{M}$ in rat hepatocytes, a concentration higher than the ones tested in our current work [24].

Finally, we found that 7D-desulfo-CYN caused no significant cell death compared to the vehicle control at $1 \mu \mathrm{M}(0.4 \mu \mathrm{g} / \mathrm{mL})$ and $5 \mu \mathrm{M}(2.0 \mu \mathrm{g} / \mathrm{mL})$ after a $48-\mathrm{h}$ treatment (Figure 7D). In the same manner, no significant viability loss was detected using $1 \mu \mathrm{M}$ and $5 \mu \mathrm{M}$ of the in-house degradation product desulfo-CYN. The vehicle control cells were grown in culture medium containing $0.2 \% \mathrm{MeOH}$ to account for the methanol content of the purified desulfo analogs' fractions.

Several authors have stated the essential role of the guanidine, uracil and hydroxyl groups in the toxic mechanism of CYN [23,31-33]. On the other hand, it has been proposed that the sulfate group of CYN has no role in its toxicity or its transport through the rat hepatocyte's membrane. According to Runnegar et al., the sulfate group at C-12 of CYN is not required to induce a protein synthesis inhibition, nor is it required for cellular uptake in primary rat hepatocytes (PRH) [31]. In the current work, no significant apoptosis nor necrosis was detected in HepG2 cells after stimulation with up to $5 \mu \mathrm{M}$ of two different desulfo variants. This incongruence can be explained by taking into account the cell type (PRH) and, also, the kind of biological activity assays (protein synthesis and cellular glutathione quantitation) used by Runnegar et al. (2002). Direct and indirect protein synthesis in vitro measurements are sensitive and specific of CYN alkaloids' biological activity; these tests may not correlate well with cell viability assays (detection of the onset of necrosis and apoptosis). Likewise, PRH are known to be more sensitive to the toxic mechanisms of CYN. PRH display a wide variety 
of metabolic enzymes, membrane receptors and active transport proteins that resemble the liver parenchyma [6,34,35]. The HepG2 hepatoma cell line lacks this diversity, making it less sensitive to the toxicity of CYN alkaloids [12,35]. Taking this into account, it is likely that higher doses of desulfo-CYN and 7D-desulfo-CYN are necessary to detect their lethal potency in HepG2 cells.

Interestingly, 7-deoxy-desulfo-CYNs tend to be less-hydrophilic than the zwitterionic alkaloids (according to the n-octanol and water partition coefficients in Figure 1). Lipophilicity, commonly represented by the $\log \mathrm{P}$ value, is the definitive factor in a molecule's absorption, diffusion across cellular and tissue membranes, metabolism and excretion. Thus, a correlation between the lipophilicity and biological activity of small molecules is usually made [36,37]. In this way, the deoxy-desulfo analogs are favored with a better chance of passive membrane transport. Nevertheless, the enhanced capacity of desulfated analogs to penetrate cell membranes in comparison to zwitterionic species was not reflected in their lethality towards HepG2 cells. Only the original cylindrospermopsin alkaloid was able to significantly decrease viability in the hepatoma cell line at the tested conditions.

It has been demonstrated that 7D-desulfo-CYN and 7D-CYN correspond to the last two biosynthetic steps of CYN [19]. In the last biosynthetic step, the cyrI gene of the cyr cluster encodes a 2-oxoglutarate-dependent hydroxylase that transforms 7-deoxy-cylindrospermopsin into the diastereomers CYN and 7-epi-CYN [20]. The pharmacological significance of the C-7 hydroxyl group lies in being the last modification of a complex biosynthetic pathway in order to enable its biological activity. Previously, synthetic CYN analogs were used by other authors to test the pharmacological importance of the C-7 hydroxyl group [32,33]. Studies by Cartmell et al. (2017) compared the bioactivity of several synthetic analogs, revealing that the hydroxyl group at C-7 was indispensable in causing significant toxicity in human cells. The authors proposed that the C-7 hydroxyl group may be crucial for the active cellular transportation of CYN, analogous to the uptake of cholesterol. Evans et al. (2019) tested the biological activity of new synthetic CYN analogs with variations in their functional groups but all possessing the uracil ring. These experiments showed that the C-7 hydroxyl group, as well as the guanidine moiety, have a role in cylindrospermopsin's toxicity and that both are essential for the molecule's biological activity [33].

The toxicity assays presented in this work indicate that, in our biological model, a combination of the guanidino, uracil, sulfate and C-7 hydroxyl functional groups is necessary for a CYN analog to efficiently induce cell death. Future investigations using desulfo CYN variants may include toxicity tests using 3D hepatocyte cultures, toxicity tests on PRH cultures and in vivo toxicokinetics studies. The isolation workflow proposed by our group may serve useful for the forthcoming research of uncommon CYN alkaloids.

\section{Materials and Methods}

\subsection{Cylindrospermopsis raciborskii Strain Maintenance}

The Cylindrospermopsis raciborskii strain $11 \mathrm{~K}$ is an Australian strain provided by Professor Marli Fatima Fiori at the Centro de Energía Nuclear na Agricultura (CENA), Universidade de São Paulo (Campus Luiz de Queiroz, Piracicaba). This strain produces CYN, 7D-CYN and 7D-deoxy-CYN. A Brazilian non-CYN-producing strain (C. raciborskii ITEP 18) was grown and used as a matrix for CYN spiked-in extractions during the validation of the LC-DAD method. These strains were maintained in our laboratory using the ASM-1 culture medium proposed by Gorham et al. (1964), with some modifications [38,39].

Both cyanobacterial strains were cultured inside an incubator at the desired final volume, with a working temperature of $22{ }^{\circ} \mathrm{C}$, a 12-h light/dark interval and a light intensity of 30 to $50 \mu \mathrm{mol}$. photons. $\mathrm{m}^{-2} \cdot \mathrm{s}^{-1}$; calibrated by a LI-COR ${ }^{\circledR} 250 \mathrm{~A}$ (LI-COR, Lincoln, NE, USA) light meter. 


\subsection{Tests on Sample Size and Cartridge Handling for Liquid Samples}

Extraction experiments to assess the adsorption of the analytes in two different SPE sorbents required liquid samples obtained from the Cylindrospermopsis raciborskii strain $11 \mathrm{~K}$ cultures with a density of $1 \times 10^{8}$ cells/mL.

Each lot of approximately $20 \mathrm{~L}$ of dense culture broth was centrifuged $\left(10,000 \mathrm{rpm}, 10 \mathrm{~min}, 4^{\circ} \mathrm{C}\right)$, and the supernatant (liquid medium) was collected. The remaining precipitate (filamentous cells or cellular debris) was frozen at $-20^{\circ} \mathrm{C}$ before lyophilization. Next, we filtered the culture medium through a $0.44-\mu \mathrm{m}$ membrane to avoid clogging of the SPE cartridges.

Small-scale experiments using the liquid medium were performed initially to assess the adsorption of the analytes (mostly CYN and 7D-CYN) on two SPE columns: C18 Sep-Pak $1 \mathrm{~g}$ (Waters ${ }^{\circledR}$, Milford, MA, USA) and graphitized nonporous carbon (GNPC) Envi-carb 1g (Supelco ${ }^{\circledR}$, Bellefonte, PA, USA). On the first experiment, SPE columns were pretreated with $10 \mathrm{~mL}$ of $\mathrm{MeOH}$, followed by $10 \mathrm{~mL}$ of water. After the SPE column conditioning, we applied $300 \mathrm{~mL}$ of liquid medium to each cartridge through a PTFE (polytetrafluoroethylene) tubing system connected by a SPE tube adapter. The adsorbed analytes were eluted using $5 \mathrm{~mL}$ of each of the following aqueous solutions: $10 \%, 50 \%, 75 \%$ and $100 \% \mathrm{MeOH}$ (Figures S1-S5). The GNPC cartridges were eluted in backflush mode (or reverse mode) due to the high affinity of the analytes to the stationary phase. The recovered volumes were dried and concentrated in 200- $\mu \mathrm{L} 50 \% \mathrm{MeOH}$ before LC-DAD analysis.

Another small-scale experiment using the liquid medium was aimed to evaluate the percent recovery of CYNs using two elution techniques for the GNPC cartridges. GNPC columns were pretreated initially with $10 \mathrm{~mL}$ of $\mathrm{MeOH}$. After this step, we applied $10 \mathrm{~mL}$ of water to each SPE column. Once the SPE columns were conditioned, we applied $300 \mathrm{~mL}$ of the liquid medium to each cartridge through the PTFE tubing system. The adsorbed analytes were eluted using two elution techniques: $\mathrm{MeOH}: \mathrm{CH}_{2} \mathrm{Cl}_{2}(4: 1) 5 \% \mathrm{FA}$ (3 fractions of $5 \mathrm{~mL}$ ) using the cartridge in the usual forward mode or $10 \%, 50 \%$ and $100 \% \mathrm{MeOH}$ (3 fractions of $5 \mathrm{~mL}$ ) using the cartridge in backflush mode (Figure S6). The recovered volumes were dried and concentrated in $200 \mu \mathrm{L}$ of $50 \% \mathrm{MeOH}$. We calculated the $100 \%$ recovery of every $\mathrm{CYN}$ alkaloid by quantitating the analytes on a lyophilized sample of the filtrated culture medium. LC-DAD-MS ${ }^{2}$ was used to carry out the analysis in order to improve the confirmation of CYN variants at low recoveries.

Large-scale experiments using the liquid medium were performed to test the affinity of the analytes (mostly CYN and 7D-CYN) to the GNPC column when using larger sample volumes (1.5-4 L). GNPC cartridges were pretreated using $10 \mathrm{~mL}$ of $\mathrm{MeOH}$, followed by $10 \mathrm{~mL}$ of water. After this conditioning step, we applied the desired volume of the liquid medium to the cartridge through the PTFE tubing system. Arbitrary volumes of 1.5, 3 and $4 \mathrm{~L}$ were applied once to each GNPC column. We eluted the adsorbed analytes once with $10 \mathrm{~mL}$ of $\mathrm{MeOH}: \mathrm{CH}_{2} \mathrm{Cl}_{2}$ (4:1) 5\% FA. The recovered eluates and effluents (Figure S6) were dried and concentrated in 200- $\mu \mathrm{L} 50 \% \mathrm{MeOH}$ before LC-DAD-MS ${ }^{2}$ analysis.

\subsection{Tests on Sample Size and Cartridge Handling for Solid Samples}

Biomass experiments were intended to optimize the 7D-desulfo-CYN isolation from a complex sample. The biomass samples used in the present work consisted of lyophilized filamentous cells or cellular debris. We obtained these cyanobacterial remnants from the frozen precipitates derived from the centrifugation of dense culture broths of the Cylindrospermopsis raciborskii strain $11 \mathrm{~K}$, as stated earlier. After weighing the lyophilized sample, cells were suspended in $50 \% \mathrm{MeOH}$. In this suspension, cell membranes were disrupted using an ultrasonic probe sonicator. The lysate was centrifuged $\left(10,000 \mathrm{rpm}, 10 \mathrm{~min}, 4^{\circ} \mathrm{C}\right)$, and the supernatant was transferred to a clean tube. The pellet was resuspended with $50 \% \mathrm{MeOH}$, sonicated, centrifuged and the supernatant was collected and mixed with the previous extract. The final extract was filtered through a $0.44 \mu \mathrm{m}$ membrane and diluted with water to approximately $1 \% \mathrm{MeOH}$. These aqueous extracts were later permeated through the desired SPE columns through the PTFE tubing system. 
The biomass experiments tested the adsorption of the analytes to the sorbents of Oasis HLB $0.5 \mathrm{~g}$ and C18 Sep-Pak $0.5 \mathrm{~g}$ cartridges (Waters ${ }^{\circledR}$, Milford, MA, USA). The affinity of the analytes to the SPE sorbents while adjusting the sample's $\mathrm{pH}(\mathrm{pH} 4,7$ and 10) was also studied. The SPE columns were pretreated with 6-mL 100\% MeOH, followed by $6 \mathrm{~mL}$ of water. While permeating the aqueous samples through the columns, the resulting effluent was collected and later lyophilized for analysis. We eluted the analytes from the sorbents with 6-mL $10 \% \mathrm{MeOH}$, followed by $6 \mathrm{~mL}$ pure $\mathrm{MeOH}$. Both fractions were also collected for every sample. A similar experiment was performed with $\mathrm{C} 18$ cartridges only, in which the cartridges were eluted using 10-mL 15\% $\mathrm{MeOH}$, followed by $10 \mathrm{~mL}$ of pure $\mathrm{MeOH}$ (all fractions were collected for every sample).

\subsection{Semipreparative Purification}

The isolation of high-purity CYNs from the biomass or broth using SPE columns usually required this last purification step. We resuspended the GNPC extracts in Milli-Q ${ }^{\circledR}$ (MilliporeSigma, Burlington, MA, USA) grade $\mathrm{H}_{2} \mathrm{O}$ and $\mathrm{C} 18$ extracts in 20\% MeOH (to improve 7D-desulfo-CYN's solubility) before the chromatographic separation using a Luna $5 \mu \mathrm{m}$ C18 100A, $250 \times 10 \mathrm{~mm}$ (Phenomenex ${ }^{\circledR}$, Torrance, CA, USA) HPLC column. The mobile phase consisted of Milli-Q ${ }^{\circledR}$ grade $\mathrm{H}_{2} \mathrm{O}$, and elution of the CYN variants was achieved with a gradual increase of $\mathrm{MeOH}$ from 5\% to $80 \%$ for $35 \mathrm{~min}$. The semipreparative purification was carried out using an HPLC (LC20AD, Shimadzu Corporation, Kyoto, Japan) with a diode-array detector (SPD-M20A) coupled to a fraction collector (FRC-10A, Shimadzu Corporation, Kyoto, Japan). Detection of the CYN structural analogs was set between 200 and $600 \mathrm{~nm}$ using the diode-array detector.

\subsection{Sample Preparation for LC-DAD Method Validation}

A cyanobacterial strain confirmed by our lab as a nonproducer of CYN (C. raciborskii ITEP 18) was grown according to Section 4.1 and used as a matrix for CYN spiked-in extractions. Cultures with a density of $1 \times 10^{8}$ cells/mL were centrifuged, and the supernatant was collected. The resulting liquid medium was divided into aliquots, each with a volume of $300 \mathrm{~mL}$. Acyclovir-certified standard (Thermo Fisher Scientific, Waltham, MA, USA) was used as the IS. Calibrators and control samples were prepared using different lots of CYN-certified standards (Eurofins Abraxis, Warminster, PA, USA).

\subsection{LC-DAD Method Validation}

Validation of the LC-DAD method was performed following regulatory guidelines established by the National Agency for Sanitary Vigilance, document RDC No. 166 (Brazil 2017) [40,41]. The assessed validation parameters were linearity, limits of detection (LOD), limits of quantification (LOQ), selectivity, carryover, within-day bias and within-day imprecision.

Linearity $\left(R^{2} \geq 0.99\right)$ was estimated by the analysis of calibration curves $(n=5)$. Calibrators were prepared at the following concentrations: $0.5,5,25,50,100$ and $150 \mu \mathrm{g} / \mathrm{mL}$. These calibrators were considered acceptable at $\leq 15 \%$ coefficient of variation (CV) ( $\leq 20 \% \mathrm{CV}$ at the lower LOQ).

Estimation of the LOD and LOQ was performed using decreasing concentrations of CYN-spiked samples. The lower LOD was the lowest concentration, with a signal/noise ratio $\geq 3$, and the lower LOQ was the lowest concentration, with a signal/noise ratio $\geq 10$.

Within-day imprecision and within-day bias were calculated at five concentrations in five replicates. Imprecision was expressed as the coefficient of variation ( $\% \mathrm{CV})$. Acceptable imprecision was $\leq 15 \% \mathrm{CV}$ ( $\leq 20 \% \mathrm{CV}$ at the lower LOQ was accepted). Bias was estimated for each concentration as the relative standard error (\% RSE). Relative standard errors of $85-115 \%$ were considered acceptable, and $80-120 \%$ RSE were accepted at the lower LOQ.

The matrix effect was evaluated using blank samples. Interference in the DAD detector's response was tested at the retention times of CYN and IS (acyclovir). Interference peaks of $\leq 20 \%$ of the analyte response at the lower LOQ were considered acceptable. Interference peaks of $\leq 5 \%$ of the IS response were considered acceptable. 
Chromatographic selectivity was evaluated by calculating the peak resolution (Rs) of a nonextracted mix containing the following analytes: CYN (certified standard), acyclovir (certified standard), 7D-CYN (purified fraction), 7D-desulfo-CYN (purified fraction) and desulfo-CYN. The desulfo-CYN degradation product was synthesized by diluting a purified fraction of cylindrospermopsin in an aqueous solution of $\mathrm{HCl} 5 \%$ and maintaining it in constant shaking at $70{ }^{\circ} \mathrm{C}$ during a 48 -h interval.

\subsection{LC-DAD-MS Instrumentation}

The extracts were separated through a Synergi $4 \mu \mathrm{m}$ Hydro-RP 80A, $150 \times 4.6 \mathrm{~mm}$ (Phenomenex ${ }^{\circledR}$, Torrance, CA, USA) HPLC column, protected with a guard column of the same material. The mobile phase consisted of 5-mmol/L ammonium acetate buffer with $0.05 \%$ FA. Several gradient elutions using $\mathrm{MeOH}$ were tested, according to Eaglesham et al. (1999) [42] and Gallo et al. (2009) [1]. The gradient elution of the final method started at a 100\% aqueous mobile phase, with a gradual increase up to $80 \%$ $\mathrm{MeOH}$ at $15 \mathrm{~min}$ (flow $0.2 \mathrm{~mL} / \mathrm{min}$ ). Samples were resuspended in $50 \% \mathrm{MeOH}$, and $5 \mathrm{uL}$ was injected into an HPLC (LC20AD, Shimadzu Corporation, Kyoto, Japan) with a diode-array detector (SPD-M20A, Shimadzu Corporation, Kyoto, Japan), coupled to a quadrupole time-of-flight mass spectrometer (Micro TOF-QII; Bruker Daltonics, Billerica, MA, USA) with an ESI (electrospray ionization) interphase.

The detection range for CYNs' quantitation was set between 200 and $600 \mathrm{~nm}\left(\lambda_{\max }=262 \mathrm{~nm}\right)$ using the diode-array detector. Since the diode-array detector was coupled to the Micro TOF-QII analyzer, quantitation and structure confirmation of CYN and structural analogs were carried out simultaneously. The ionization source conditions were as follows: capillary potential of $3500 \mathrm{~V}$, temperature and flow of drying gas (nitrogen) of $300{ }^{\circ} \mathrm{C}$ and $5 \mathrm{~mL} / \mathrm{min}$, respectively, and a nebulizer pressure of $35 \mathrm{psi}$. Mass spectra were acquired using electrospray ionization in the positive mode, $m / z$ range 50 to 3000 . The Micro TOF-QII instrument was operated in MS ${ }^{1}$ scan mode or MS ${ }^{2}$ MRM (multiple reaction monitoring) mode as needed. In the MRM mode, CID (collision-induced dissociation) experiments were performed using the following collision energies for fragmentation: $20 \mathrm{eV}, 35 \mathrm{eV}$ and $40 \mathrm{eV}$.

\subsection{Toxicity of the CYN Variants}

HepG2 cells (Code 0103) purchased from Rio de Janeiro Cell Bank (BCRJ, Rio de Janeiro, Brazil) were grown in DMEM (Dulbecco's Modified Eagle's medium) high glucose (Gibco ${ }^{\circledR}$, Thermo Fisher Scientific, Waltham, MA, USA) supplemented with 10\% fetal bovine serum (FBS), $100 \mathrm{U} / \mathrm{mL}$ penicillin and $0.1 \mu \mathrm{g} / \mathrm{mL}$ streptomycin at $37^{\circ} \mathrm{C}$ in a $5 \% \mathrm{CO}_{2}$ atmosphere. HepG2 cells were seeded in 6-well plates with a density of $2.5 \times 10^{5}$ cells/well, incubated overnight and treated with the chosen CYN variant at the desired time interval. After the treatment intervals, cells were rinsed with phosphate-buffered saline (PBS). The cells were detached from the flask using $300 \mu \mathrm{L}$ of $2.5 \mathrm{~g} / \mathrm{L}$ trypsin solution $(0.25 \%$ trypsin diluted in PBS) for $5 \mathrm{~min}$. DMEM with $10 \%$ FBS $(3 \mathrm{~mL})$ was added to inactivate the trypsin, transferred to the collection tubes and centrifuged at $250 \times g$ for $5 \mathrm{~min}$ at $4{ }^{\circ} \mathrm{C}$. The supernatant was discarded, and the pellet was washed using PBS with $4 \%$ FBS, followed by $200 \mu \mathrm{L}$ of annexin V-binding buffer (10 $\mathrm{mM}$ Hepes pH 7.4, $140 \mathrm{mM} \mathrm{NaCl}$ and $2.5 \mathrm{mM} \mathrm{CaCl}_{2}$ ). We stained the cells using $5 \mu \mathrm{L}$ of annexin $\mathrm{V}$ conjugated with allophycocyanin (annexin V-APC) $\left(\mathrm{BD}^{\mathrm{TM}}\right.$, East Rutherford, NJ, USA) and $2 \mu \mathrm{L}$ of propidium iodide (PI) (Sigma-Aldrich, St. Louis, MO, USA). The samples were incubated for $15 \mathrm{~min}$ in the dark at room temperature. Cells treated with 10\% dimethyl sulfoxide and with $40 \%$ methanol were used as positive controls for apoptosis and necrosis, respectively, and cells without any treatment were used as the negative control. We analyzed the samples on a flow cytometer FACS Canto II (BD ${ }^{\mathrm{TM}}$, East Rutherford, NJ, USA), acquiring 10,000 events using the FACS Diva ${ }^{\mathrm{TM}}$ software, version $8.0\left(\mathrm{BD}^{\mathrm{TM}}\right.$, East Rutherford, NJ, USA). The excitation wavelength was $\lambda_{\mathrm{EX}} 633 \mathrm{~nm}$ and $480 \mathrm{~nm}$ and emission at $\lambda_{\mathrm{EM}} 660 \mathrm{~nm}$ and $578 \mathrm{~nm}$ for annexin V-APC and PI, respectively. The samples were analyzed using FlowJo software version 8.0 (BD ${ }^{\mathrm{TM}}$, Ashland, OR, USA). The analysis was conducted in quadruplicate, and the results were expressed as mean \pm the standard deviation. Statistical comparisons between groups (control vs. treatment) were performed using Mann-Whitney U tests; $p<0.05$ was considered statistically significant. 
Supplementary Materials: The following are available online. Table S1: Calculated log P of CYN structural analogs according to three different cheminformatics tools. Figure S1: Sample's effluent from C18 (red chromatogram) or from GNPC (green chromatogram) cartridges. Figure S2: Sample elution using 5-mL 10\% MeOH from C18 (red chromatogram) or from GNPC (green chromatogram) cartridges. Figure S3: Sample elution using 5-mL 50\% $\mathrm{MeOH}$ from $\mathrm{C} 18$ (red chromatogram) or from GNPC (green chromatogram) cartridges. Figure S4: Sample elution using 5-mL 75\% MeOH from C18 (red chromatogram) or from GNPC (green chromatogram) cartridges. Figure S5: Sample elution using 5-mL MeOH from C18 (red chromatogram) or from GNPC (green chromatogram) cartridges. Table S2: Percent recovery comparison of CYN, 7D-CYN and 7D-desulfo-CYN on GNPC cartridges using two elution techniques: $\mathrm{MeOH}: \mathrm{CH}_{2} \mathrm{CL}_{2}$ (4:1) 5\% FA using the cartridge on the usual forward mode (3 fractions of $5 \mathrm{~mL}$ ) or $10 \%, 50 \%$ and $100 \% \mathrm{MeOH}$ on cartridge-backflush mode (3 fractions of $5 \mathrm{~mL}$ ). Figure S6: Sample's effluent from a GNPC cartridge acquired on a LC-DAD-MS ${ }^{2}$. Figure S7: Assay linearity in liquid medium samples analyzed on a LC-DAD. Table S3: Selected analytical performance parameters, criteria and experimental results for the final method. Table S4: Criteria, experimental data and status for within-day precision and bias of 5 levels of quality control liquid medium samples $(n=5)$. Figure S8: Chromatographic separation of CYN and four similar analytes on a Synergi Hydro-RP (C18) column acquired in a LC-DAD-MS².

Author Contributions: Conceptualization, C.G.-B., F.A.D. and E.P.; methodology, C.G.-B., R.A., J.O. and F.A.D.; software, C.G.-B., R.A. and F.A.D.; validation, C.G.-B.; formal analysis, C.G.-B. and R.A.; investigation, C.G.-B. and F.A.D.; resources, E.P. and J.O.; data curation, C.G.-B.; writing-original draft preparation, C.G.-B.; writing-review and editing, C.G.-B., F.A.D., R.A., J.O. and E.P.; visualization, C.G.-B.; supervision, E.P. and J.O.; project administration, E.P. and funding acquisition, E.P. All authors have read and agreed to the published version of the manuscript.

Funding: This work was supported by the São Paulo State Research Foundation (FAPESP—Grant \#2014/50420-9), University of São Paulo Foundation (FUSP-Grant \#1979), the Coordination for the Improvement of Higher Education Personnel (CAPES-Grant \#23038.001401/2018-92) and CNPq (Grant \#311048/2016-1 \& 439065/2018-6). $\mathrm{EP}$ is a researcher fellowship recipient from $\mathrm{CNPq}$.

Conflicts of Interest: The authors declare no conflicts of interest.

\section{References}

1. Gallo, P.; Fabbrocino, S.; Cerulo, M.G.; Ferranti, P.; Bruno, M.; Serpe, L. Determination of cylindrospermopsin in freshwaters and fish tissue by liquid chromatography coupled to electrospray ion trap mass spectrometry. Rapid Commun. Mass Spectrom. 2009, 23, 3279-3284. [CrossRef] [PubMed]

2. Bittencourt-Oliveira Mdo, C.; Piccin-Santos, V.; Moura, A.N.; Aragao-Tavares, N.K.; Cordeiro-Araujo, M.K. Cyanobacteria, microcystins and cylindrospermopsin in public drinking supply reservoirs of Brazil. An. Acad. Bras. Ciências 2014, 86, 297-310. [CrossRef] [PubMed]

3. Azevedo, S.M.; Carmichael, W.W.; Jochimsen, E.M.; Rinehart, K.L.; Lau, S.; Shaw, G.R.; Eaglesham, G.K. Human intoxication by microcystins during renal dialysis treatment in Caruaru-Brazil. Toxicology 2002, 181-182, 441-446. [CrossRef]

4. Moreira, C.; Azevedo, J.; Antunes, A.; Vasconcelos, V. Cylindrospermopsin: Occurrence, methods of detection and toxicology. J. Appl. Microbiol. 2013, 114, 605-620. [CrossRef] [PubMed]

5. Dörr, F.A.; Pinto, E.; Soares, R.M. Microcystins in South American aquatic ecosystems: Occurrence, toxicity and toxicological assays. Toxicon 2010, 56, 1247-1256. [CrossRef] [PubMed]

6. Sadler, R. Towards a more complete understanding of the occurrence and toxicities of the cylindrospermopsins. AIMS Environ. Sci. 2015, 2, 827-851. [CrossRef]

7. Molinspiration-Cheminformatics. Molinspiration. Available online: https://www.molinspiration.com/cgibin/properties (accessed on 5 May 2020).

8. ChemAxon. Chemicalize. Available online: https://chemicalize.com/ (accessed on 5 May 2020).

9. Tetko, I.V.; Gasteiger, J.; Todeschini, R.; Mauri, A.; Livingstone, D.; Ertl, P.; Palyulin, V.A.; Radchenko, E.V.; Zefirov, N.S.; Makarenko, A.S.; et al. Virtual computational chemistry laboratory-design and description. J. Comput. Aided Mol. Des. 2005, 19, 453-463. [CrossRef]

10. Daina, A.; Michielin, O.; Zoete, V. SwissADME: A free web tool to evaluate pharmacokinetics, drug-likeness and medicinal chemistry friendliness of small molecules. Sci. Rep. 2017, 7, 42717. [CrossRef]

11. Li, R.; Carmichael, W.; Brittain, S.; Eaglesham, G.; Shaw, G.; Mahakhant, A.; Noparatnaraporn, N.; Yongmanitchai, W.; Kaya, K.; Watanabe, M. Isolation and identification of the cyanotoxin cylindrospermopsin and deoxy-cylindrospermopsin from a Thailand strain of Cylindrospermopsis raciborskii (Cyanobacteria). Toxicon 2001, 39, 973-980. [CrossRef] 
12. Neumann, C.; Bain, P.; Shaw, G. Studies of the comparative in vitro toxicology of the cyanobacterial metabolite deoxycylindrospermopsin. J. Toxicol. Environ. Health Part A 2007, 70, 1679-1686. [CrossRef]

13. Norris, R.L.; Eaglesham, G.K.; Pierens, G.; Shaw, G.R.; Smith, M.J.; Chiswell, R.K.; Seawright, A.A.; Moore, M.R. Deoxycylindrospermopsin, an analog of cylindrospermopsin from Cylindrospermopsis raciborskii. Environ. Toxicol. 1999, 14, 163-165. [CrossRef]

14. Shaw, G.R.; Seawright, A.A.; Moore, M.R.; Lam, P.K.S. Cylindrospermopsin, a cyanobacterial alkaloid: Evaluation of its toxicologic activity. Ther. Drug Monit. 2000, 22, 89-92. [CrossRef] [PubMed]

15. Wimmer, K.M.; Strangman, W.K.; Wright, J.L.C. 7-Deoxy-desulfo-cylindrospermopsin and 7-deoxydesulfo-12-acetylcylindrospermopsin: Two new cylindrospermopsin analogs isolated from a Thai strain of Cylindrospermopsis raciborskii. Harmful Algae 2014, 37, 203-206. [CrossRef]

16. Banker, R.; Teltsch, B.; Sukenik, A.; Carmeli, S. 7-Epicylindrospermopsin, a Toxic Minor Metabolite of the Cyanobacterium Aphanizomenon o valisporum from Lake Kinneret, Israel. J. Nat. Prod. 2000, 63, 387-389. [CrossRef]

17. Norris, R.; Eaglesham, G.; Shaw, G.; Senogles, P.; Chiswell, R.; Smith, M.; Davis, B.; Seawright, A.; Moore, M. Extraction and purification of the zwitterions cylindrospermopsin and deoxycylindrospermopsin from Cylindrospermopsis raciborskii. Environ. Toxicol. 2001, 16, 391-396. [CrossRef] [PubMed]

18. Ohtani, I.; Moore, R.E.; Runnegar, M.T. Cylindrospermopsin: A potent hepatotoxin from the blue-green alga Cylindrospermopsis raciborskii. J. Am. Chem. Soc. 1992, 114, 7941-7942. [CrossRef]

19. Mihali, T.K.; Kellmann, R.; Muenchhoff, J.; Barrow, K.D.; Neilan, B.A. Characterization of the gene cluster responsible for cylindrospermopsin biosynthesis. Appl. Environ. Microbiol. 2008, 74, 716-722. [CrossRef] [PubMed]

20. Mazmouz, R.; Essadik, I.; Hamdane, D.; Méjean, A.; Ploux, O. Characterization of CyrI, the hydroxylase involved in the last step of cylindrospermopsin biosynthesis: Binding studies, site-directed mutagenesis and stereoselectivity. Arch. Biochem. Biophys. 2018, 647,1-9. [CrossRef]

21. Kubo, T.; Sano, T.; Hosoya, K.; Tanaka, N.; Kaya, K. A new simply and effective fractionation method for cylindrospermopsin analyses. Toxicon 2005, 46, 104-107. [CrossRef] [PubMed]

22. Davis, T.W.; Orr, P.T.; Boyer, G.L.; Burford, M.A. Investigating the production and release of cylindrospermopsin and deoxy-cylindrospermopsin by Cylindrospermopsis raciborskii over a natural growth cycle. Harmful Algae 2014, 31, 18-25. [CrossRef] [PubMed]

23. Banker, R.; Carmeli, S.; Werman, M.; Teltsch, B.; Porat, R.; Sukenik, A. Uracil moiety is required for toxicity of the cyanobacterial hepatotoxin cylindrospermopsin. J. Toxicol. Environ. Health Part A 2001, 62, 281-288. [CrossRef]

24. Looper, R.E.; Runnegar, M.T.; Williams, R.M. Synthesis of the putative structure of 7-deoxycylindrospermopsin: C7 oxygenation is not required for the inhibition of protein synthesis. Angew. Chem. Int. Ed. 2005, 44,3879-3881. [CrossRef] [PubMed]

25. Looper, R.E.; Runnegar, M.T.C.; Williams, R.M. Syntheses of the cylindrospermopsin alkaloids. Tetrahedron 2006, 62, 4549-4562. [CrossRef]

26. Dorr, F.A.; Tomaz, J.C.; Lopes, N.P.; Pinto, E. Comparative analysis of the gas-phase reactions of cylindrospermopsin and the difference in the alkali metal cation mobility. Rapid Commun. Mass Spectrom. 2008, 22, 2015-2020. [CrossRef]

27. Froscio, S.M.; Fanok, S.; Humpage, A.R. Cytotoxicity screening for the cyanobacterial toxin cylindrospermopsin. J. Toxicol. Environ. Health Part A 2009, 72, 345-349. [CrossRef] [PubMed]

28. Straser, A.; Filipic, M.; Zegura, B. Genotoxic effects of the cyanobacterial hepatotoxin cylindrospermopsin in the HepG2 cell line. Arch. Toxicol. 2011, 85, 1617-1626. [CrossRef] [PubMed]

29. Gutiérrez-Praena, D.; Guzmán-Guillén, R.; Pichardo, S.; Moreno, F.J.; Vasconcelos, V.; Jos, Á.; Cameán, A.M. Cytotoxic and morphological effects of microcystin-LR, cylindrospermopsin, and their combinations on the human hepatic cell line HepG2. Environ Toxicol 2019, 34, 240-251. [CrossRef] [PubMed]

30. Štraser, A.; Filipič, M.; Gorenc, I.; Žegura, B. The influence of cylindrospermopsin on oxidative DNA damage and apoptosis induction in HepG2 cells. Chemosphere 2013, 92, 24-30. [CrossRef]

31. Runnegar, M.T.; Xie, C.; Snider, B.B.; Wallace, G.A.; Weinreb, S.M.; Kuhlenkamp, J. In vitro hepatotoxicity of the cyanobacterial alkaloid cylindrospermopsin and related synthetic analogues. Toxicol. Sci. 2002, 67, 81-87. [CrossRef] 
32. Cartmell, C.; Evans, D.M.; Elwood, J.M.L.; Fituri, H.S.; Murphy, P.J.; Caspari, T.; Poniedziałek, B.; Rzymski, P. Synthetic analogues of cyanobacterial alkaloid cylindrospermopsin and their toxicological activity. Toxicol. In Vitro 2017, 44, 172-181. [CrossRef]

33. Evans, D.M.; Hughes, J.; Jones, L.F.; Murphy, P.J.; Falfushynska, H.; Horyn, O.; Sokolova, I.M.; Christensen, J.; Coles, S.J.; Rzymski, P. Elucidating cylindrospermopsin toxicity via synthetic analogues: An in vitro approach. Chemosphere 2019, 234, 139-147. [CrossRef] [PubMed]

34. Lopez-Alonso, H.; Rubiolo, J.A.; Vega, F.; Vieytes, M.R.; Botana, L.M. Protein synthesis inhibition and oxidative stress induced by cylindrospermopsin elicit apoptosis in primary rat hepatocytes. Chem. Res. Toxicol. 2013, 26, 203-212. [CrossRef]

35. Pichardo, S.; Cameán, A.M.; Jos, A. In Vitro Toxicological Assessment of Cylindrospermopsin: A Review. Toxins 2017, 9, 402. [CrossRef]

36. Leo, A.; Hansch, C.; Elkins, D. Partition coefficients and their uses. Chem. Rev. 1971, 71, 525-616. [CrossRef]

37. Klopman, G.; Zhu, H. Recent methodologies for the estimation of n-octanol/water partition coefficients and their use in the prediction of membrane transport properties of drugs. Mini Rev. Med. Chem. 2005, 5, 127-133. [CrossRef] [PubMed]

38. Gorham, P.R.; McLachlav, J.R.; Hammer, V.T.; Kim, W.K. Isolation and culture of toxic strain of Anabaena flos-aquae. Proc. Int. Assoc. Theor. Appl. Limnol. 1964, 15, 794-804.

39. Bortolli, S.D. Guia Prático Para Manutenção e Cuidados da Coleção de Cianobacterias do LTPNA; Universidade de São Paulo, Laboratório de Toxinas e Produtos Naturais de Algas (LTPNA), Faculdade de Ciências Farmacéuticas.: São Paulo, Brazil, 2011.

40. Ministério da Saúde, ANVISA. RDC n. ${ }^{\circ}$ 166. Available online: http://portal.anvisa.gov.br/documents/10181/ 2721567/RDC_166_2017_COMP.pdf/d5fb92b3-6c6b-4130-8670-4e3263763401 (accessed on 5 May 2020).

41. Ministério da Saúde, ANVISA. RDC n. ${ }^{\circ}$ 27. Available online: http://bvsms.saude.gov.br/bvs/saudelegis/ anvisa/2012/rdc0027_17_05_2012.html (accessed on 5 May 2020).

42. Eaglesham, G.K.; Norris, R.L.; Shaw, G.R.; Smith, M.J.; Chiswell, R.K.; Davis, B.C.; Neville, G.R.; Seawright, A.A.; Moore, M.R. Use of HPLC-MS/MS to monitor cylindrospermopsin, a blue-green algal toxin, for public health purposes. Environ. Toxicol. 1999, 14, 151-154. [CrossRef]

(C) 2020 by the authors. Licensee MDPI, Basel, Switzerland. This article is an open access article distributed under the terms and conditions of the Creative Commons Attribution (CC BY) license (http://creativecommons.org/licenses/by/4.0/). 